\title{
The NRAMPI, VDR and TNF- $\alpha$ Gene Polymorphisms in Iranian Tuberculosis Patients: The Study on Host Susceptibility
}

\begin{abstract}
Muayad Merza ${ }^{1}$, Parissa Farnia ${ }^{1}$, Sabar Anoosheh ${ }^{1}$, Mohammed Varahram ${ }^{1}$, Mehdi Kazampour ${ }^{1}$, Omid Pajand ${ }^{1}$, Shima Saeif ${ }^{1}$, Mehdi Mirsaeidi ${ }^{1}$, Mohammad Reza Masjedi ${ }^{1}$, Ali Akbar Velayati ${ }^{1}$ and Sven Hoffner ${ }^{2}$

${ }^{1}$ Mycobacteriology Research Centre, National Research Institute of Tuberculosis and Lung Disease (NRITLD), Shahid Beheshti University

(Medical Campus), Darabad, Tehran, Iran; ${ }^{2}$ Department of Bacteriology, Swedish Institute for Infectious Disease control, Solna, Sweden
\end{abstract}

\begin{abstract}
The natural resistance-associated macrophage protein (NRAMP1), Vitamin-D receptor (VDR) and Tumor necrosis factor $(\mathrm{TNF}-\alpha)$ have been associated in susceptibility to tuberculosis, but the results have been inconsistent. This study aimed to determine the association of NRAMP1, VDR, and TNF-á variant with development of pulmonary tuberculosis (PTB) among Iranian patients. The single nucleotide polymorphisms (SNPs) at INT4, D543, 3'UTR of NRAMP1 gene, SNPs in restriction sites of BsmI, and FokI of the VDR gene and SNPs of TNF- $\alpha$ at -238,-308, -244,857,-863 positions were analyzed by PCR-RFLP among two groups of individual; patients with PTB (n=117) and healthy controls $(n=60)$. Thereafter, the frequencies of extended haplotypes and diplotypes were estimated. No statistically significant differences were observed in allele frequencies of INT4, D543, 3'UTR of NRAMPI, FokI of VDR and TNF- $\alpha$ at $-238,-244,-863$ and -857 position. Although, the frequency of $b$ allele of BsmI [ORs: 0.24 CI95\% ( 0.07-0.67 $(p=0.001)]$ and -308 A variant in TNF- $\alpha$ promoter region [ORs:0.26 CI95\%( 0.07-0.77) $(p=0.006)]$ were significantly more in PTB patients than healthy controls. The frequency of extended diplotypes of NRAMP [GG TGTG++GA; 0.02(0.001-0.0035)], VDR [FFBB; 0.2(0.6-0.6] and TNF- $\alpha$ [CCCCGGGGGG; 0.49(0.25-0.97)] were statistically different in patients and control subjects $(p<0.05)$. This study confirmed the association of SNPs in BsmI (B/b + b/b) of VDR and SNPs in -308A (G/A +G/G) of TNF- $\alpha$ genes with susceptibility to tuberculosis in Iranian PTB patients. Furthermore, the extended haplotypes and diplotypes analysis can be considered as an alternative way to determine the host susceptibility to TB.
\end{abstract}

Key-Words: NRAMP, VDR, TNF- $\alpha$ gene, tuberculosis.

Tuberculosis is one of the most common infectious diseases in the world [1]. Generally, the risk of developing disease in infected individuals, ranges from $5 \%$ to $10 \%$ [2]. This suggest that besides the Mycobacteria itself, the host genetic factors may determine the differences in host susceptibility to TB [3]. Recently, a number of genes have been investigated in various case control studies, among which the natural resistance-associated macrophage protein (NRAMP1, also called as solute carrier 11a1; Slc11a1), vitamin$\mathrm{D}$ receptor (VDR) and tumor necrosis factor-alpha (TNF- $\alpha$ ) genes are thought to be important in the intracellular killing of Mycobacteria [4-6]. The NRAMP1 is the human homologue of the mouse Nramp1 gene, and is present on human chromosome 2q35 [7,8]. Vitamin-D receptor (VDR) gene is located on chromosome $12 \mathrm{q}$ and has several common allelic variants [9]. NRAMP1 and VDR exerts immuno-modulatory effects, which activates the monocytes and restrict the growth of MTB in macrophages [10]. The TNF- $\alpha$ gene that encodes the cytokines TNF- $\alpha$ is located within the class III region of the MHC. TNF- $\alpha$ is an important mediator in the inflammatory response against $\mathrm{TB}$ and its production controlled both transcriptionally and post transcriptionally $[6,11,12]$. Polymorphisms in the NRAMP1, VDR and TNF- $\alpha$ genes have

Received on 6 April 2009; revised 3 July 2009.

Address for correspondence: Dr. P. Farnia, Mycobacteriology Centre, NRITLD, Shahid Beheshti University (Medical Campus), Tehran, 19556, P.O:19575/154, IRAN, Fax No: 00982120109505. E-mail: pfarnia@hotmail.com. Web site:http://www.nritld.

The Brazilian Journal of Infectious Diseases

2009;13(4):252-256. (C) 2009 by The Brazilian Journal of Infectious Diseases and Contexto Publishing. All rights reserved. been associated in susceptibility to tuberculosis in different ethnic groups [13-15], but the results have been inconclusive. The aim of this study was to investigate the association NRAMP1, VDR and TNF- $\alpha$-genes polymorphisms in Iranian PTB patients. Furthermore, the combination of the alleles of the studied genes were assessed. To our knowledge this is the first report on the single nucleotide polymorphisms (SNPs) of TNF- $\alpha$ at $-244,-857$ and -863 positions in TB patients.

\section{Material and Methods \\ Data Collection}

The study, involved 117 newly smear positive TB patients that were referred to Iranian National Reference TB Laboratory patients from January 2007 to January 2008. All the patients had positive AFB smear microscopy results and their Chest X-ray (CXR) had classical picture of TB, i.e., upper lobe infiltration with presence of cavities. Sixty healthy individuals were included in this study as controls (The Institutional Review Board at the NRITLD approved the study, and all the patients have signed informed consent). The healthy individuals were selected from nurses, doctors and TB staff which were working in NRITLD during the last 10 years. Therefore, our control cases were already exposed to infection. They had positive PPD test result with no laboratory or clinical sign of diseases development. Patients and control subjects were matched for age, sex and nationality.

\section{DNA Isolation}

Genomic DNA was extracted using the standard protocol with slight modifications [13]. Briefly, Peripheral Blood Leukocytes (PBLs) were separated from two milliliters of the 
whole blood using RBC lysis buffer $\left(0.155 \mathrm{M} \mathrm{NH}_{4} \mathrm{Cl}, 0.01 \mathrm{M}\right.$ $\mathrm{NaHCO}_{3}$ ). Thereafter, PBLs re-suspended in $500 \mu \mathrm{L}$ of SE buffer ( $\mathrm{NaCl} 3 \mathrm{M}$, EDTA $0.5 \mathrm{M}, \mathrm{PH}=8$ ), containing $40 \mu \mathrm{L}$ of $10 \%$ SDS and $3 \mu \mathrm{L}$ of $20 \mathrm{mg} / \mathrm{mL}$ of proteinase $\mathrm{K}$. The suspension was incubated at $60^{\circ} \mathrm{C}$ for 30 minutes. After incubation, $200 \mu l$ of equilibrated phenol $(\mathrm{PH}=8)$ was added to the mixture and centrifuged for $10 \mathrm{~min}$ at $12,000 \mathrm{~g}$. The aqueous phase transferred to a new tube and the DNA was precipitated using cold propanol.

\section{Nramp1 Genotyping}

Nramp1 genomic polymorphisms were determined using the Polymerase Chain Reaction (PCR) and then Restriction fragment length polymorphisms (PCR-RFLP) [13,14]. Each polymorphism was named accordingly: a $\mathrm{G} / \mathrm{C}$ single nucleotide change in intron $4(469+14 \mathrm{G} / \mathrm{C})$ was termed INT-4, a non conservative single base substitution at codon 543 that changes aspartic acid (Asp) to asparagine (Asn) was termed D543N, and a TGTG deletion in the 3' un-translated region (1729+55del4) was termed 3'UTR. PCR was performed in a total volume of $50 \mu \mathrm{L}$ of solution, containing $0.1 \mu \mathrm{g}$ of genomic DNA, $5 \mu \mathrm{L} \mathrm{Mg}^{2+}$ free10X PCR buffer (Roch Diagnostic GmbH, Germany ), $200 \mu \mathrm{M}$ dntps, $1.5 \mathrm{mM} \mathrm{MgCl}_{2}, 0.4 \mu \mathrm{M}$ of each primer and 2.5 unit Taq DNA polymerase (Roch). Thermal cycling was performed on a TC-412 device (Techne, Cambridge, UK). For D543 and 3'UTR Nramp1 polymorphism, the reaction was allowed to continue for $3 \mathrm{~min}$ at $94^{\circ} \mathrm{C}$, denaturation for $1 \mathrm{~min}$ at $94^{\circ} \mathrm{C}$, annealing for $1 \mathrm{~min}$ at $55^{\circ} \mathrm{C}$, extension for $1 \mathrm{~min}$ at $72^{\circ} \mathrm{C}$ repeated at 30 cycles and $3 \mathrm{~min}$ at $72^{\circ} \mathrm{C}$, then store at $4^{\circ} \mathrm{C}$. With INT-4, annealing was done at $56^{\circ} \mathrm{C}$ for $1 \mathrm{~min}$ [16], all other procedures were identical. The INT4 fragment (623 bp) was amplified using 5'-CTC TGG CTG AAG GCT CTC C-3' and 5'TGT GCT ATC AGT TGA GCC TC primer. A region of $244 \mathrm{bp}$ for D543N and 3'UTR were amplified using 5-GCA TCT CCC CAATTC ATG G-3' and 5'-AAC TGT CCC ACT CTATCC TG3 ' primers [13,17].

\section{PCR-RFLP of NRAMP 1}

ApaI was used for INT-4 and with the $\mathrm{G} \rightarrow \mathrm{C}$ mutant type; two bands of 455bp and 169bp were verified. AvaII was used for D543N with allele G (Asp) showing three bands of 126bp, 79bp and 39bp, and A (Asn) showing at two bands of 201bp and 33bp. FokI was used for 3UTR with allele TGTG ${ }^{+}$showing 211bp and 33bp fragments and del showing a 240bp fragment $[13,16]$. Digested products were run on $8 \%$ polyacrylamide gel, which were stained with Silver-Nitrate.

\section{VDR Genotyping}

VDR gene poymorphisms were studied using PCR and RFLP. For FokI polymorphisms, the following primers were used to amplify a 265 bp product from the region flanking exon 2 of VDR gene:5' AGC TGG CCC TGG CACTGA CTC TGC TCT-3'; 5'AG GAAACA CCT TGC TTC TTC TCC CTC3'. For BsmI polymorphisms, the following primers were used to amplify a 825bp product: 5' CAACCAAGA CTA CAA GTA
CCG CGT CAG TGA-3';5’AAC CAG CGG GAA GTAAAG GG-3'.Cycling conditions for all reaction involved 30 cycles of denaturation at $94^{\circ} \mathrm{C}$ for $1 \mathrm{~min}$, annealing at $60^{\circ} \mathrm{C}$ for $1 \mathrm{~min}$, and extension at $72^{\circ} \mathrm{C}$ for $1 \mathrm{~min}$ [17].

\section{PCR-RFLP of VDR}

PCR products were digested in an excess of restriction enzyme for $3 \mathrm{~h}\left(\right.$ at $65^{\circ} \mathrm{C}$ ) with BsmI at $37^{\circ} \mathrm{C}$ and with FokI [18]. Digested products were run on $8 \%$ polyacrylamide gel, and were stained with Silver- Nitrate. The presence of a restriction site was assigned a lowercase letter and its absence an uppercase letter, according to the convention (Table 1).

\section{TNF- $\alpha$ Genotyping}

TNF- $\alpha$ gene polymorphisms was studied using PCR and RFLP. For TNF -308 polymorphisms, the following primers were used to amplify a 107bp product:5' AGC AAT AGG TGG TTT TGA CTC GGGC CCAT-3';5’TCC TCC CTG CTC CGA TTC CG-3'. For -238 and-244 polymorphisms, the following primers were used to amplify a 230 bp product: 5'CCT CAA GGA CTC CAA AGC TTT CTG -3'; 5’ACA CTC CCC ATC CTC CCA GATC -3'. For -857 polymorphisms, the following primers were used to amplify a 127 bp product: 5' GGC TCT GAG GAATGG GTT AC-3';5’CCT CTACAT GGC CCT GTC TAC-3'. The amplification was accomplished by an initial denaturattion at $94^{\circ} \mathrm{C}$ for $5 \mathrm{~min}$, and 30 cycles at $94^{\circ} \mathrm{C}$ for $40 \mathrm{~s}$, at $56^{\circ} \mathrm{C}$ for $40 \mathrm{~s}$, at $72^{\circ} \mathrm{C}$ for $1 \mathrm{~min}$, followed by an extension at $72^{\circ} \mathrm{C}$ for $6 \min [19]$.

\section{PCR-RFLP of TNF- $\alpha$}

PCR products of, TNF -238, -244, TNF -308,TNF -857 and TNF-863 were digested with 2 U enzymes of BgI II, Bsaj I, NcoI, TaiI and TaiI,respectively [15,19]. Digested products were run on $8 \%$ polyacrylamide gel, and were stained with Silver-Nitrate.

\section{Statistical Analyses}

The frequency of the genotypes in patients and controls groups were estimated by direct gene counting and then the data analysed using SPSS version 11( SPSS Inc, Chicago, IL, U.S.A). In order to test the Hardy-Weinberg equilibrium, all frequencies of various genotypes were compared using the chi-square test. The odds ratio and p-value were calculated for each allele in patient and control groups. All p value was two tailed. A p-value of less than $<0.05$ was considered significant with 95\% confidence intervals (CI). Haplotypes combination of the alleles of different genes were analyzed using fisher exact test.

\section{Results}

Allele Frequencies of NRAMP1 Gene Polymorphisms

$26.7 \%$ of control subjects had heterozygote mutant alleles (G/A variants) for D543 loci, in comparison to 5\% in TB cases $(\mathrm{p}=0.0000)[\mathrm{ORs}: 6.4 \mathrm{CI}$ 95\%(2.29-22.1)] (Table 1). For INT4 and 3'UTR locus, the heterozygosity were equally represented 
Table 1. Relation between Nramp1,VDR \& TNF- $\alpha$ polymorphisms and tuberculosis in Iranian studied cases.

\begin{tabular}{|c|c|c|c|c|c|}
\hline Genotypes & $\begin{array}{c}\text { No }(\%) \text { of } \\
\text { patients with } \\
\text { PTB =117 }\end{array}$ & $\begin{array}{c}\text { No }(\%) \text { of } \\
\text { control } \\
\text { subjects }=60\end{array}$ & $\begin{array}{l}\text { x2 test for overall } \\
\text { genotypic } \\
\text { frequency } \\
\text { (p value) }\end{array}$ & $\begin{array}{l}\text { x2 test for } \\
\text { individual } \\
\text { genotypic } \\
\text { frequency } \\
\text { (p value) }\end{array}$ & OR (95\% CI) \\
\hline \multicolumn{6}{|l|}{ NRAMP INT4 } \\
\hline C/C (uncut) & $1(0.9 \%)$ & 0 & & & \\
\hline G/C (heterozygote) & $39(33.3 \%)$ & $20(33.3 \%)$ & $0.52(\mathrm{p}=1.000)$ & & \\
\hline G/G (homozygote) & $77(65.8 \%)$ & $40(66.7 \%)$ & & & \\
\hline \multicolumn{6}{|l|}{ NRAMP D543 } \\
\hline G/G ((frequent type) & $111(94.9 \%)$ & $44(73.3 \%)$ & & & \\
\hline G/A (heterozygote) & $6(5.1 \%)$ & $16(26.7 \%)$ & $16.9(\mathrm{P}=0.000)^{*}$ & & $\mathrm{G} / \mathrm{A}+\mathrm{G} / \mathrm{G}=6.4(2.29-22.13)$ \\
\hline A/A (homozygote) & $0(0.0 \%)$ & 0 & & & \\
\hline \multicolumn{6}{|l|}{ NRAMP 3'UTR } \\
\hline TGTG+/+ (frequent type) & $110(94 \%)$ & $57(95.0 \%)$ & & & \\
\hline TGTG+/del (heterozygote) & 7(6. \%) & $3(5.0 \%)$ & $0.072(\mathrm{p}=1.000)$ & & \\
\hline TGTG del/del (homozygote) & $0(0.0 \%)$ & $0(0.0 \%)$ & & & \\
\hline \multicolumn{6}{|l|}{ VDR-fokI } \\
\hline f/f (homozygote) & $4(3.4 \%)$ & $0(0.0 \%)$ & & & \\
\hline F/f (heterozygote) & $46(39.3 \%)$ & $25(41.7 \%)$ & $2.11(\mathrm{P}=0.348)$ & & \\
\hline F/F (frequent type) & $67(57.3 \%)$ & $35(58.3 \%)$ & & & \\
\hline \multicolumn{6}{|l|}{ VDR bsmI } \\
\hline b/b (homozygote) & $43(36.8 \%)$ & $26(43.3 \%)$ & & & \\
\hline B/b (heterozygote) & $67(57.3 \%)$ & $21(35.0 \%)$ & $13.03(\mathrm{p}=0.001)^{*}$ & $-0.157(p=0.001)$ & $\mathrm{B} / \mathrm{b}+\mathrm{b} / \mathrm{b}=0.24(0.07-0.67)$ \\
\hline B/B (frequent type) & $7(6.0 \%)$ & $13(21.7 \%)$ & & & \\
\hline \multicolumn{6}{|l|}{ TNF-238 } \\
\hline G/A (heterozygote) & $9(7.7 \%)$ & $3(5.0 \%)$ & & & \\
\hline G/G (homozygote) & $108(92.3 \%)$ & $57(95.0 \%)$ & $0.0455(\mathrm{p}=0.552)$ & & \\
\hline A/A (frequent type) & $0(0.0 \%)$ & $0(0.0 \%)$ & & & \\
\hline \multicolumn{6}{|l|}{ TNF-308 } \\
\hline A/A (frequent type) & $3(2.6 \%)$ & $0(0.0 \%)$ & & & \\
\hline G/A (heterozygote) & $24(20.5 \%)$ & $4(6.7 \%)$ & $7.6(\mathrm{p}=0.02)^{*}$ & $-0.164(p=0.006)$ & $\mathrm{A} / \mathrm{G}+\mathrm{G} / \mathrm{G}=0.26(0.07-0.77)$ \\
\hline G/G (homozygote) & $90(76.9 \%)$ & $56(93.3 \%)$ & & & \\
\hline \multicolumn{6}{|l|}{ TNF-244 } \\
\hline G/G (frequent type) & $117(100 \%)$ & $60(100 \%)$ & & & \\
\hline \multicolumn{6}{|l|}{ TNF-863 } \\
\hline A/A (homozygote) & $0(0.0 \%)$ & $1(1.7 \%)$ & & & \\
\hline C/A (heterozygote) & $35(29.9 \%)$ & $20(33.3 \%)$ & $2.25(\mathrm{p}=0.325)$ & & \\
\hline C/C (frequent type) & $82(70.1 \%)$ & $39(65.0 \%)$ & & & \\
\hline \multicolumn{6}{|l|}{ TNF-857 } \\
\hline C/T (heterozygote) & $42(35.9 \%)$ & $18(30.0 \%)$ & & & \\
\hline C/C (frequent type) & $69(59.0 \%)$ & $42(70.0 \%)$ & $4.2(\mathrm{p}=0.119)^{*}$ & $-0.11(\mathrm{p}=0.181)$ & $\mathrm{C} / \mathrm{T}+\mathrm{T} / \mathrm{T}=0.162(0.3-1.25)$ \\
\hline T/T (homozygote) & $6(5.1 \%)$ & $0(0.0 \%)$ & & & \\
\hline
\end{tabular}

among patients and the control subjects. No individual carried the homozygous mutant alleles at D543 (A/A) and 3’UTR (D/ D). At INT4 loci only single TB cases had homozygous variant of $\mathrm{C} / \mathrm{C}$. In overall, the number of uncut or wild types of INT4 (G/G), D543 (G/G) and 3UTR (TGTG+/+) polymorphisms were higher than its corresponding mutant types $(\mathrm{p}<0.05)$.

Allele Frequencies of VDR Gene Polymorphisms Each of FokI and BsmI of VDR polymorphisms showed three types of patterns; frequent homozygote allele (wild type), infrequent heterozygote and infrequent homozygote alleles (mutant type). The frequency of FokI polymorphisms were FF: Ff: $\mathrm{ff}=57.3 \%$ : 39.3\%: $3.4 \%$ for patients and $58.3 \%$ : $41 \%$ : $0 \%$ in control cases. For BsmI, the total number of infrequent allele ( B/b + b/b) was more in TB cases( 94\%)than control subjects (78\%) $(\mathrm{p}=0.001)$ [ORs: 0.24 CI95\% (0.07-0.67)]. The frequency of $\mathrm{BB}$ genotype was $21.7 \% \%$ in control subjects versus $6 \%$ in TB cases (Table 1 ). 
Allele Frequencies of TNF- $\alpha$ Gene Polymorphisms

The results in Table 1 showed the five polymorphisms in TNF- $\alpha$ gene, a $G$ to A substitution at position-308, a $G$ to $A$ substitution at position -238, a $\mathrm{C}$ to $\mathrm{T}$ substitution at position857, a C to A substitution at position -863, and a $\mathrm{G}$ to $\mathrm{A}$ substitution at position-244. No statistical difference was observed in the allele frequencies of TNF-238 C/A and TNF863C/A in control and TB cases. Although, the frequency of 308A allele were more in TB cases (23.1\%) than control subjects (6.7\%) $(\mathrm{p}=0.006)$ [ORs:0.26 CI95\%( 0.07-0.77)]. No individual with mutant allele were found at TNF- $\alpha 244$ positions. The TNF- $\alpha-857$ T allele was more in TB cases (41\%) than control subjects but the differences were not statistically significant ( $p=0.181)[$ ORs:0.162 CI95\% (0.3-0.77)].

Haplotypes and diplotypes analysis of NRAMP, VDR \& TNF$\alpha$ gene polymorphisms

In both groups, the most frequent haplotypes of NRAMP gene were GTGTG+G (77\%) and CTGTG+G (15\%). Haplotype GTGTG+A were seen among control cases only [8.3\%, ORs:0.02 CI95\% (0.001-0.38)]. The diplotyping of NRAMPI showed an 8 different patterns, out of which GATGTG+/+GG (55.9\%) and GCTGTG+/+GG (29.9\%) represents the most frequent one. In control cases, the frequency of GGTGTG+/ +GA was $16.7 \%$ versus $0 \%$ in TB cases [ORs:0.02 CI95\% (0.001-0.035)]. For two VDR polymorphisms, four haplotypes ( $\mathrm{fB}, \mathrm{fb}, \mathrm{FB}, \mathrm{Fb}$ ) were identified. Although, their frequencies were same in both groups and no statistical differences were observed in them. The frequencies of FFBb (31.6\%) and FfBb (24\%) diplotypes were higher in patients (31.6\%; 24.8\%) than controls $(11.3 \% ; 23.3 \%)(\mathrm{p}<0.05)$. For five TNF- $\alpha$ gene polymorphisms, nine haplotypes and ninteen diplotypes were identified. The ACGGG, CCGGG and CTGGG were the most frequent haplotypes in both groups. The overall distribution of diplotypes of TNF- $\alpha$ gene was different between TB and control subjects. The following diplotypes were found in TB case only; CAAAGAGGGG(6\%),CCTTGGGGGG(3.4\%), CCCCGAGGAG (1.7\%). Haplotypes combination of the alleles of different genes showed GTGTG+GFBCCGGG and GTGTG+GFBCCGGG as a dominant allele frequencies, in both studied groups. Although, the CTGTG+GFBACGGG (7.3\%),CTGTG+GFBCCGGG (5.4\%), CTGTG+GFBACGGG (3.2\%) frequencies were detected in TB cases only. In contrast, the frequencies like GTGTG+GFbCTGGG (7.8\%), GTGTG+GFBCCGGA(6.2\%), and GTGTG+GfbCTAGG (3.1\%) were found in control groups $(\mathrm{p}<0.05)$.

\section{Discussion}

The polymorphisms in the 5' and 3' regions of the NRAMP1 gene have been studied in relation to tuberculosis in many populations $[7,8]$. Some studies have shown association only with the severe forms of tuberculosis, but not with susceptibility to tuberculosis. We found no association between allele variants at locus INT4, D543 and 3'UTR of NRAMPI in patients versus healthy control (Table 1). Similar to our finding, Vejbaesya et al. showed no association of INT4, D543 and 3'UTR of NRAMPI variants with susceptibility to TB or with the severe forms of TB, in the Thai population [16]. By contrast, in the other Asians groups, the D543 and 3'UTR variants were associated with presence of cavity lesions or other severe forms of diseases [19,20]. In overall, the frequency of NRAMPI polymorphisms was demonstrated to be variable in various ethnical groups $[12,16,19,20]$. The most likely explanation for these apparently divergent findings is genetic heterogeneity in the phenotype control. It has been clearly established that the impact of NRAMPI on tuberculosis susceptibility is best detected when gene-gene or geneenvironment interactions are taken into account in the analysis $[16,19,20]$. In a study carried out in pulmonary TB patients of south India, the Bb genotype of VDR BsmI was associated with susceptibility to TB, whereas AA genotype of ApaI and $\mathrm{BB}$ genotype of BsmI were associated with resistance to pulmonary TB $[18,21,22]$. In another study, the frequency of $\mathrm{Bb}$ genotype was higher in spinal TB than healthy controls [22]. In fact, various diallelic polymorphisms have been identified in the vitamin $\mathrm{D}$ receptor gene and these polymorphic variants have been shown to be associated with susceptibility or resistance to tuberculosis [18,21,22]. Our data reconfirmed the association of BsmI polymorphisms ( $\mathrm{Bb}+\mathrm{bb})$ with tuberculosis. Although, the frequency of FF genotype of VDR FokI was more than its corresponding mutant one, in both studied groups (Table 1). In total, 58.3\% of PTB cases and $57.3 \%$ of control subjects had FF alleles. Generally, the VDR gene with FF genotype demonstrated an increased transcription rate, and this has provided the main explanation for association between FokI genotype and the development of diseases. Previous studies showed 65\% frequency of FF genotype among Indian PTB patients and 62\% among westAfricans [14,18]. Although in Chinese and Peruvian the frequency was lowered to 24 and $9 \%$, respectively [21,23]. In present study, the frequency of FF genotype was close to Indian communities.

In TNF- $\alpha$ promoter gene (-238 and -308) two SNPs have been described, and the presence of $\mathrm{A}$ at -308 has been associated with the high TNF- $\alpha$ production $[6,15,19]$. Today, several polymorphisms have been found in TNF gene at position -1031, -863, -857, -575, -376, -308, -244, -238, and +70 [19]. Although, the polymorphisms in position,-238, and -308 have been extensively studied in tuberculosis [24,25]. Previous studies demonstrated no association of particular allele or genotype of TNF- $\alpha$ with TB in different Asians, i.e., Indian, Turkish and Thai population [6,16,26]. In this study, only TNF$\alpha$-308A allele was associated with pulmonary TB (Table 1).Similar to our finding, Bikmaeva et al. suggested an association of -308A allele with risk of pulmonary TB [26]. Generally, $\mathrm{G}$ to A substitution at position -308 represents a functional polymorphism which leads to different transcription rates in TNF- $\alpha$ production. In present study, the functionality of these polymorphisms were not evaluated. Therefore, we suggested a further study to verify the effect of

www.bjid.com.br 
polymorphisms in susceptibility to tuberculosis among Iranian PTB cases. Basically, the study of single nucleotide polymorphisms is a traditional approach and today investigators determine the frequency of haplotypes or diplotypes polymorphisms for identifying the candidate genes in molecular epidemiology $[14,22,27]$. In our study, no significant difference was observed in the frequency of haplotypes in the studied groups. Although, haplotypes combination of NRAMP, VDR and TNF- $\alpha$ genes resulted in frequencies (15\%-16\%) that were seen in TB cases, only $(\mathrm{p}<0.05)$.Therefore, haplotype or diplotype variables can be considered as an alternative way to study the SNPs of NRAMPI, VDR and TNF- $\alpha$ genes in susceptibility to tuberculosis.

\section{Conclusions}

The molecular studies would contribute to better understanding the pathogenic processes that underlie major infectious diseases by allowing a more systematic study of the genetic influences. We know that the development of tuberculosis is the result of a complex interaction between the host and pathogen influenced by environmental factors. And numerous host genes are likely to be involved in this process. Here, we showed the association of $b$ allele of BsmI and TNF$\alpha-308 \mathrm{~A}$ variants in susceptibility to TB. Based on these findings we might suggest, further prospective studies to investigate the possible interaction of VDR and TNF- $\alpha-308 \mathrm{~A}$ variants in PTB development.

\section{Acknowledgements}

We thank all the TB patients and their families who have patiently helped us to complete the required information. The project was founded by MRC/NRITLD/WHO grant no, 011223-2007. There is no competting interest.

\section{References}

1. Dubos R, Dubos J. The Whites Plague: Tuberculosis, Man and Society, Little Brown and Co., Boston,1952.

2. Frieden TR, Sterling TR, Munsiff SS, et al. Tuberculosis. Lancet 2003;362:887-899.

3. Bellamy R. Susceptibility to Mycobacterial infections: the importance of host genetics.Genes Immun 2003;4:4-11.

4. Bellamy R, Beyers N,McAdam KP, et al.Genetic susceptibility to tuberculosis in Africans: a genome -wide scan. Proc Natl Acad Sci USA 2000;97:8005-8007.

5. Zmuda JM, Cauley JA, Ferrell RE. Molecular Epidemiology of Vitamine D receptor gene variants. Epidemiologic Reviews. 2000;22:203-217.

6. Ates O, Nusellim B, Ongen G, Sarikaya TA. Interleukin-10 and tumour necrosis factor- $\alpha$ gene polymorphisms in tuberculosis. J Clin Immunol 2007;28:232-236.

7. Cellier M, Govoni G,Vidal S, et al. Human natural resistance associated macrophage protein: cDNA cloning, chromosomal mapping, genomic organization, and tissue-specific expression. J Exp Med 1994;180:1741-1752.
8. Goto Y, Buschman E,Skamene E. Regulation of host resistance to Mycobacterium intracellular in vivo and in in vitro by the Bcg gene. Immunogenetics 1989;30:218-221.

9. Rockett KA,Brookes R, Udalova I, et al. 1,25- Ddihydroxyvitamin D3 induces nitric oxide synthase and suppresses growth of Mycobacterium tuberculosis in a human macrophage-like cell line. Infect Immun 1998;66:5314-21.

10. Lemire JM, Adams JS, Sakai R, Jordan SC. 1-alpha 25Dihydroxyvitamin D3 suppresses proliferation and immunoglobulin production by normal human peripheral blood mononuclear cells. J.Clin.Invest. 1984;74:657-661.

11. Rook GA, Steele J, Fraher L, et al. Vitamin D3, gamma interferon, and control of proliferation of Mycobacterium tuberculosis by human monocytes. Immunology 1986;57:159-63.

12. Lin PL, Plessner HL,Voitenko N V, Flynn JA.Tumour necrosis factor and tuberculosis. J.Invest.Dermatology 2006;12:22-25.

13. Kim JH, Lee SY, Lee SH, et al.NRAMP1 genetic polymorphisms as a risk factor of tuberculoses pleurisy. Int $\mathrm{J}$ Tuberc Lung Dis 2002; 7:370-375.

14. Bornman L, Campbell SJ, Fielding K, et al. Vitamin D receptor polymorphisms and susceptibility to Tuberculosis in west-Africa: A case- control and family study.Infect Disease. 2004:190:16311641.

15. Oh JH,Yang S, NohYK, e at.Polymorphisms of interleukin-10 and tumour necrosis factor genes are associated with newly diagnosed and recurrent pulmonary tuberculosis. Respirology 2007:12;594-598.

16. Vejbaesya S, Chierakul N,Luangtrakool P,Sermduangprateep C. NRAMPI and TNF-Alpha polymorphisms and susceptibility to tuberculosis in Thais. Respiratory. 2007;12:202-206.

17. Babb C, Merwe V.D, Beyers N, et al. Vitamine D receptor gene polymorphisms and sputum conversion time in pulmonary tuberculosis patients. Tuberculosis 2007;87:295-302.

18. Selvaraj P, Chandra G, Kurian SM, et al. Association of vitamin D receptor gene variants of BsmI, ApaI and FOKI polymorphisms with susceptibility or resistance to pulmonary tuberculosis. Current Science 2003;84:1564-1568.

19. Ryu S, Park YK,Baj GH, et al. 3'UTR polymorphisms in the NRAMPI gene are associated with susceptibility to tuberculosis in Koreans. Int.J.Tuberc.Lung Dis 2000;4:577-80.

20. Zhang W, Shao L, Weng X. et al. Variants of the natural resistanceassociated macrophage protein 1 gene (NRAMP!) are associated with severe forms of pulmonary tuberculosis. Clin. Infect. Dis. 2005;40:1232-6.

21. Roth DE,Soto G, Arenas F, et al.Association between vitamin -D receptor gene polymorphisms and response to treatment of pulmonary tuberculosis.J Infect Diseases 2004;920-927.

22. Selvaraj P, Kurian SM, Chandra G etal. Vitamin D receptor gene variants of BsmI, ApaI, TagI and FOKI polymorphisms in spinal tuberculosis. Clin Genet 2004;65:73-6.

23. Liu W, Cao WC, Zhang CY, et al. VDR and NrampI gene polymorphisms in susceptibility to pulmonary tuberculosis among the Chinese Han population: a case -control study. Int J Tuberc Lung Diseases 2004;8:428-34.

24. Henao MI, Montes C, Paris SC, Garcia LF. Cytokine gene polymorphisms in Colombian patients with different clinical presentations of tuberculosis. Tuberculosis 2006;86:11-9.

25. Oliveira MMD, Da Silva JCS, Costa JF, et al. Single nucleotide polymorphisms of the TNF-alpha (-238/-308)gene amonf TB and non TB patients: Susceptibility markers of TB occurrence. Jornal Brasileiro de Pneumologia 2004;4:461-6.

26. Naito M, Miyaki K, Naio T, et al. Association between vitamin D receptor gene haplotypes and chronic periodontitis among Japanese man. Int J.Med Sci 2007;4:216-22. 